\title{
Predatory overtones of open-field testing in chickens
}

\author{
SUSAN D. SUAREZ and GORDON G. GALLUP, JR. \\ State University of New York, Albany, New York 12222
}

\begin{abstract}
Based on a model which holds that open-field behavior is due in large part to an interaction between social separation and the threat of predation, seven experiments were conducted to examine the relationship between tonic immobility and open-field activity in chickens. The results showed that placement in an open field prior to testing for tonic immobility reliably enhanced the duration of immobility. Similarly, procedures that have been shown to modify the length of the immobility episode had a comparable effect on the timing of activity onset in an open field. Since tonic immobility has been independently implicated as a putative predator defense, the correspondence between open-field behavior and tonic immobility was taken as indirect support for the hypothesis that open-field testing contains overtones of predation.
\end{abstract}

While open-field testing has traditionally been used to assess general emotionality in a number of species (Archer, 1973; Walsh \& Cummins, 1976), we have suggested that open-field behavior might be better conceptualized within an ethological framework (Gallup \& Suarez, 1980). According to our model, most studies of open-field behavior unintentionally subject animals to both predatory contact with a human during removal from the home cage and placement in the testing apparatus and sudden social separation from conspecifics. Open-field behavior can therefore be viewed as a compromise between the opposing tendencies of attempting to reinstate social contact and to evade predation.

In support of this analysis, we (Gallup \& Suarez, 1980) have shown that varying the motivation for social reinstatement in domestic chickens has predictable effects on responses, such as ambulation and separation calls in an open field, which under natural conditions serve to promote maternal or brood reunion in many birds (Bruckner, 1933; Collias, 1952; Collias \& Collias, 1956; Kruijt, 1964; Sluckin, 1965). We also demonstrated that enhancing the threat of predation during open-field testing delays the onset of vocalization and movement (i.e., freezing) which, in mammals (King, 1956), amphibians (Noble, 1931), and many avian species (Andrew, 1956; Armstrong, 1955; Leopold, 1944; Palmer, 1909; Stoddard, 1936; Stokes, 1967; White \& Weeden, 1966), occurs upon detection of a potential predator in the wild.

Ratner (1967) suggests that many prey progress through four fairly distinct behavioral stages during a predatory encounter. When an appreciable distance

This research was partially supported by a National Science Foundation predoctoral fellowship held by the first author. Reprint requests should be sent to G. G. Gallup, Jr., Department of Psychology, SUNY, Albany, New York 12222. separates prey from predator, prey typically freeze and become silent as a means of avoiding detection. If distance decreases, flight appears to be the predominant adaptive strategy. Fighting and struggling usually result when physical contact occurs. But, if contact is prolonged, tonic immobility often ensues and represents the terminal reaction in this sequence of distance-dependent defensive reactions. Tonic immobility is an unlearned state of motoric inhibition that is indexed by the absence of a righting reflex and elicited, but not maintained, by physical restraint. Other characteristics include a frozen, catatonic-like posture, suppression of vocalization, and intermittent eye closure. Tonic immobility has been observed to occur in species of several phyla, and possibly even in humans (Suarez \& Gallup, 1979). Naturalistic observations reveal that a number of prey do exhibit tonic immobility when contacted by a predator (Armstrong, 1965; Hediger, 1955; Sargeant \& Eberhardt, 1975), and recent laboratory evidence (Thompson, Foltin, Boylan, Sweet, Graves, \& Lowitz, 1981) shows that tonic immobility in quail deters predation by cats. The adaptive significance of both freezing and tonic immobility becomes obvious when one considers that sounds emitted by prey can attract predators (Busnel, 1963) and that prey movement is often a necessary condition for eliciting and maintaining orientation and/or attack (Askew, Musimeci, Sloane, \& Stephan, 1970; Burghardt, 1966; Curio, 1976; Drummond, 1979; Fox, 1969; Herzog \& Burghardt, 1974; Kaufman, 1974; MacDonald, 1973; Sisk, 1963; Smith \& Watson, 1972).

Since inhibition of both movement and vocalization can be produced in an open field by simulating a predatory encounter, and because these behaviors appear to be related to tonic immobility in that they are part of a continuum of antipredator strategies, it seemed reasonable to see if manipulations which af- 
fect tonic immobility would also affect open-field behavior. Numerous studies indicate that tonic immobility is most sensitive to presumed changes in fear in general, and to the threat of predation in particular (Gallup, 1974, 1977). The experiments reported here were designed to determine whether effects produced on tonic immobility could be used to predict open-field behavior of chicks as a means of defining the predatory overtones of open-field testing independent of the behavior they are supposed to explain.

Previous work has indicated that elicitation of initial behaviors in the defensive distance sequence can enhance responses occurring later in that sequence (Tortora \& Borschelt, 1972). The first experiment, therefore, sought to determine if the predatory overtones postulated to be intrinsic to open-field testing would have any effect on tonic immobility.

\section{EXPERIMENT 1}

In the present study, tonic immobility in chickens that had been confined to an open field before being immobilized was compared with that of subjects that had been left undisturbed prior to testing. If elicitation of antipredator behaviors earlier in the defensive distance equence potentiates those occurring later, then chic. ins that are compelled to freeze by being placed in a novel environment should show longer immobility durations than those receiving no prior predatory exposure before being immobilized.

\section{Method}

Subjects. The subjects were 40 18-day-old straight-run Production Red chickens (Gallus gallus) obtained from a commercial hatchery (Welp, Inc.) at 1 day of age. All subjects were group-housed in commercial brooders under a 14 -h photoperiod and with continuous access to chick feed and water.

Apparatus. Open-field testing was conducted at room temperature $\left(21^{\circ} \mathrm{C}\right)$ in a wooden open-field box $(88.9 \times 88.9 \times 40.6 \mathrm{~cm}$ high) with a clear Plexiglas lid under normal room illumination provided by overhead fluorescent lights. The inside of the box was painted flat black with white lines dividing the floor into a grid of 25 squares (each $17.5 \times 17.5 \mathrm{~cm}$ ). Open-field behavior was monitored with a Panasonic TV camera (WV-341P) and microphone, and filmed in an adjacent room with an International Video Corp. recorder (IVC-700) and a Panasonic VTR monitor (TR-195V).

Procedure. Twenty chicks were assigned randomly to each of two groups, and all testing was conducted during the midportion of the light half of the light-dark cycle. For one group of birds, each subject was removed from a brooder, transported to the testing room in a cardboard box, and placed in the center square of the open field. After lowering the Plexiglas lid, the experimenter sat down in a chair directly in front of the open field for the duration of the test. In order to calculate correlations between openfield behaviors and tonic immobility duration, each chick was videotaped from the time of placement until $3 \mathrm{~min}$ after it crossed out of the center square with both feet. At the completion of testing, the total number of defecations in the open field was recorded and the floor was wiped clean. Videotapes were later scored for latencies to show separation calls (also known as "distress calls"), ambulate out of the center square, defecate, and attempt to fly out of the open field. Total number of lines crossed and escape attempts were also recorded. Stopwatches were used to time latencies, and tallies were recorded on hand counters. Subjects were allowed to remain in the open field for a maximum of $\mathbf{4 0 ~ m i n}$. If a particular behavior had not occurred within this time, $2,400 \mathrm{sec}$ was assigned as the latency and zero was recorded for the corresponding frequency measure. Since the total amount of time each subject spent in the open field was dependent upon its ambulation latency score, and because defecations may be independent of ambulation, number of defecations was converted to a rate measure by the formula [number/(ambulation latency +180$)$ ] $\times 60$ as a means of equating this variable across subjects for time spent in the open field.

At the conclusion of open-field testing, each chick was tested for tonic immobility duration. An experimenter removed the bird from the open field, placed it on a nearby table, and gently restrained the subject on its right side with both hands for $15 \mathrm{sec}$. The experimenter remained in the room seated approximately $75 \mathrm{~cm}$ away from the bird and timed the immobility duration on a stopwatch from the moment of release until the bird righted itself. If immobility did not ensue after five induction attempts, each separated by $60 \mathrm{sec}$, the subject was assigned a duration score of zero.

Subjects in the other group were not given an open-field test prior to immobilization. Each chick was individually removed from a brooder, transported to the testing room in a cardboard box, and tested for tonic immobility as described above.

\section{Results}

An analysis of variance of immobility durations yielded a significant difference between groups $[F(1,36)$ $=5.21, \mathrm{p}<.03 \mathrm{]}$, with birds given an open-field test prior to immobilization remaining immobile significantly longer $($ mean $=672.6 \mathrm{sec}$ ) than those with no open-field exposure before being immobilized (mean $=272.1 \mathrm{sec}$ ). For the group that was both open-field tested and immobilized, Spearman rank-order correlations were computed between the various openfield measures and tonic immobility duration. Significant correlations with immobility duration were found for distress-call latency $(r=.44, p<.05)$, ambulation latency $(r=.56, p<.02)$, and escape latency $(\mathrm{r}=.52, \mathrm{p}<.02)$. Correlations with immobility duration were not significant for either defecation latency, number of lines crossed, or number of escape attempts, while that for defecation rate only approached significance $(r=-.39, \mathrm{p}<.10)$.

In summary, confinement in an open field under the observation of a human was effective in potentiating subsequent tonic immobility durations.

\section{EXPERIMENT 2}

Considerable evidence indicates that eye contact potentiates tonic immobility. Subjects of various species immobilized in the presence of artificial eyes exhibit longer durations of tonic immobility than do subjects for which the eyes are occluded (Gallup, Nash, \& Ellison, 1971; O'Brien \& Dunlap, 1975). The present study was conducted to determine if analogous results would obtain for open-field behavior. Accordingly, chickens were given an open- 
field test either with a pair of glass eyes suspended over the field or with the eyes masked by pieces of black tape.

\section{Method}

Subjects. Twenty-two 18-day-old straight-run Production Red chickens, obtained and maintained as in the first experiment, served as subjects.

Apparatus. Testing was conducted in the same open field and monitored with the same video equipment under the same conditions as those used in the preceding study. The artificial eyes, obtained from a taxidermist, were yellow in coloration and $1.75 \mathrm{~cm}$ in diameter with a black pupil measuring $.75 \mathrm{~cm}$ in diameter. Each eye was mounted on a wooden dowel, and the pair was suspended through holes drilled in the Plexiglas top of the open field over the center square at a distance of $11 \mathrm{~cm}$ from the top of the field. The centers of the pupils were separated by a distance of $5 \mathrm{~cm}$.

Procedure. Eleven subjects were assigned randomly to each of two groups. Each bird was individually removed from a brooder, carried to the testing room in a cardboard box, and placed in the center square of the open field. After lowering the Plexiglas lid, the experimenter left the room. For one group of birds, openfield testing was conducted with the artificial eyes suspended over the center square of the open field. For subjects in the other group, each glass eye was covered with a piece of black tape. As in the preceding study, subjects were filmed from the time of placement until $3 \mathrm{~min}$ after leaving the center square. Video tapes were scored for distress call, ambulation, and escape attempt latencies, number of lines crossed and escape attempts, and defecation rate, as described previously.

\section{Results}

Distress call and ambulation latency data are shown in Figure 1. Analyses of variance of scores corrected for heterogeneity of variance by $a \log _{10}(x+1)$ transformation revealed significant differences between groups, with birds tested in the presence of artificial eyes taking over three times longer to begin distress calling $[F(1,20)=11.48, \mathrm{p}<.005]$ and ambulating

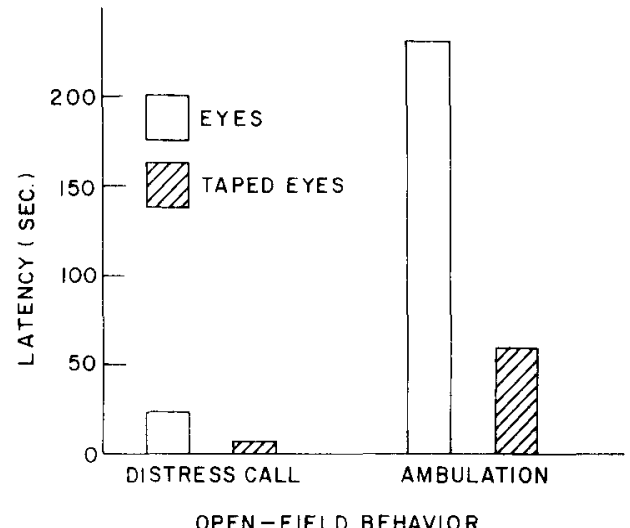

Figure 1. Mean distress-call and ambulation latency as a function of the presence of intact or occluded artificial eyes suspended over the open field.

$[F(1,20)=4.35, p<.05]$ than those for which the eyes had been masked.

Although the data were in the predicted direction (mean $=245.3$ for the eyes condition; mean $=\mathbf{8 4 . 5}$ for the masked-eyes condition), an analysis of variance of escape latency scores corrected for heterogeneity of variance by a $\log _{10}(x+1)$ transformation did not reach statistical significance $[F(1,20)=3.81, p<.065]$. Analyses of variance of the numbers of lines crossed, escape attempts, and defecation rates also yielded no significant differences between groups. Table 1 shows the Spearman rank-order correlations between the various dependent variables.

Thus, in accordance with results found in studies of tonic immobility, the presence of artificial eyes served to promote certain behaviors (i.e., delay in onset of vocalization and movement) in an open field that would be adaptive during a predatory encounter.

Table 1

Spearman Rank-Order Correlations Between Different Open-Field Behaviors in Chickens

\begin{tabular}{|c|c|c|c|c|c|c|c|c|c|c|c|c|c|}
\hline & \multicolumn{2}{|c|}{ Experiment 2} & \multicolumn{2}{|c|}{ Experiment 3} & \multicolumn{2}{|c|}{ Experiment 4} & \multicolumn{2}{|c|}{ Experiment 5} & \multicolumn{3}{|c|}{ Experiment 6} & \multicolumn{2}{|c|}{ Experiment 7} \\
\hline & Eyes & $\begin{array}{l}\text { No } \\
\text { Eyes }\end{array}$ & Noise & $\begin{array}{c}\text { No } \\
\text { Noise }\end{array}$ & $\begin{array}{l}\text { Adren- } \\
\text { alin }\end{array}$ & Water & Contact & $\begin{array}{c}\text { No } \\
\text { Contact }\end{array}$ & $\begin{array}{c}\text { Habitu- } \\
\text { ated }\end{array}$ & $\begin{array}{l}\text { Han- } \\
\text { dled }\end{array}$ & Naive & $\begin{array}{c}\text { Paci- } \\
\text { tran }\end{array}$ & Water \\
\hline $\mathrm{CL}, \mathrm{AL}$ & $.61+\dagger$ & $.68+t$ & $1.00^{*}$ & $.84 * *$ & $.82 *$ & $.79 *$ & $.53+$ & $.53+$ & $.76 *$ & $.54 \dagger$ & $.79 *$ & .15 & $.79 *$ \\
\hline DCL, LC & -.29 & -.55 & & & $-.74 * *$ & -.46 & -.10 & $-.55 t$ & $-.56 \div$ & -.30 & & .19 & -.46 \\
\hline DCL, EA & -.28 & -.19 & & & -.48 & -.38 & -.07 & -.27 & -.13 & -.16 & $-.52 t$ & .25 & -.38 \\
\hline DCL, DR & -.36 & -.34 & -.04 & -.61 & $-.58+t$ & $-.77 *$ & -.19 & -.03 & -.30 & -.37 & $-.75^{*}$ & -.19 & $-.77 *$ \\
\hline $\mathrm{AL}, \mathrm{LC}$ & -.56 & -.55 & & & $-.88^{*}$ & $-.53+t$ & -.27 & $-.60 * *$ & $-.68 *$ & -39 & $-.90 *$ & -.07 & $-.53+t$ \\
\hline $\mathrm{AL}, \mathrm{EA}$ & -.24 & -.47 & & & -.42 & -.49 & -.39 & $-.55 * *$ & .004 & -.38 & $-.64 * *$ & .24 & -.49 \\
\hline$A L, D R$ & -.60 & $-.61+t$ & -.04 & $-.72 \dagger$ & $-.63 * *$ & $-.90^{*}$ & $-.59 * *$ & -.23 & -.35 & $-.44+\dagger$ & $-.81^{*}$ & -.46 & $-.90 *$ \\
\hline LC, EA & $.81^{* *}$ & .44 & & & $.69 * *$ & $.82 *$ & $.47 \dagger \dagger$ & $.67^{*}$ & -.10 & $.72^{*}$ & $.79^{*}$ & $.71^{* *}$ & $.82 *$ \\
\hline $\mathrm{LC}, \mathrm{DR}$ & $.90^{*}$ & .58 & & & $.84^{*}$ & $.56+\dagger$ & .21 & .18 & .01 & $.50+\dagger$ & $.79^{*}$ & -.13 & $.56+t$ \\
\hline EA, DR & $.82 * *$ & .56 & & & $.51 \dagger \dagger$ & $.62 \dagger$ & $.62 * *$ & .16 & .24 & .43 & $.74^{*}$ & .17 & $.62 \dagger$ \\
\hline $\mathrm{EL}, \mathrm{DCL}$ & -.40 & .58 & $1.00 *$ & $.82 * *$ & $.87^{*}$ & $.83^{*}$ & $.51 \dagger$ & $.44+t$ & & & & .10 & $.83^{*}$ \\
\hline $\mathrm{EL}, \mathrm{AL}$ & -.38 & $.91^{*}$ & $1.00^{*}$ & $.99 *$ & $.94 *$ & $.98^{*}$ & $.93 *$ & $.71^{*}$ & & & & $.97^{*}$ & $.98 *$ \\
\hline $\mathrm{EL}, \mathbf{L C}$ & $-.60 \dagger \dagger$ & -.28 & & & $-.87^{*}$ & $-.54 \dagger \dagger$ & -.18 & $-.58 * *$ & & & & -.05 & $-.54+\dagger$ \\
\hline EL, EA & & -.54 & & & $-.52 \dagger \dagger$ & $-.53+\dagger$ & -.32 & $-.76^{*}$ & & & & .20 & $-.53+f$ \\
\hline EL, DR & & -.48 & -.04 & $-.75 t$ & $-.67^{* *}$ & $-.90 *$ & $-.60 * *$ & -.24 & & & & -.39 & $-.90^{*}$ \\
\hline
\end{tabular}

Note $-D C L=$ distress call latency, $A L=$ ambulation latency, $L C=$ lines crossed, $E A=$ escape attempts, $D R=$ defecation rate, $E L=$ escape latency. $\quad{ }^{*} p<.001 . \quad{ }^{* *} p<.01 . \quad \quad t p<.02 . \quad \quad+t_{p}<.05$. 


\section{EXPERIMENT 3}

Under natural conditions, sudden noise might serve to alert prey to an approaching predator and thereby signal the threat of a predatory encounter. Thus, it is not surprising to find that exposure to pretest noise reliably enhances immobility durations in several species (Edson \& Gallup, 1972; Gallup, Nash, Potter, \& Donegan, 1970; Nash, Gallup, \& McClure, 1970 ). Experiment 3 was conducted to determine if exposure to pretest noise of the type used in studies of tonic immobility would produce similar effects on open-field behavior.

\section{Method}

Subjects. The subjects were 20 straight-run Production Red chickens obtained and maintained as in the previous studies. Testing was conducted at 25 days of age.

Apparatus and Procedure. The same open field and video monitoring equipment were used, and testing was conducted under the same illumination conditions during the same interval of the photoperiod as described previously. Ten subjects were assigned randomly to each of two groups. Each chick was individually removed from a brooder, transported to the testing room in a cardboard box, and placed in the center square of the open field. After the Plexiglas lid was lowered, and with the experimenter out of view, birds in one group were exposed to a 5-sec tape recording of an air horn (Seaguard Air Power-Mate) measuring $85 \mathrm{dBA}$. Blank tape of the same duration was played for birds in the other group. Because of noise-induced startle effects, monitoring of open-field behavior was initiated $5 \mathrm{sec}$ after the tape recording was terminated and continued until $3 \mathrm{~min}$ after the subject ambulated out of the first square. Latencies to distress call, ambulate, and attempt to escape, and number of lines crossed, escape attempts, and defecation rate were recorded as in the preceding experiments.

\section{Results}

The latency data are shown in Figure 2. An analysis of variance of distress-call latencies corrected for heterogeneity of variance by a $\log _{10}(x+1)$ transformation yielded a highly significant difference between groups $[F(1,18)=99.03, p<.001]$, with birds in the noise group taking an average of over 100

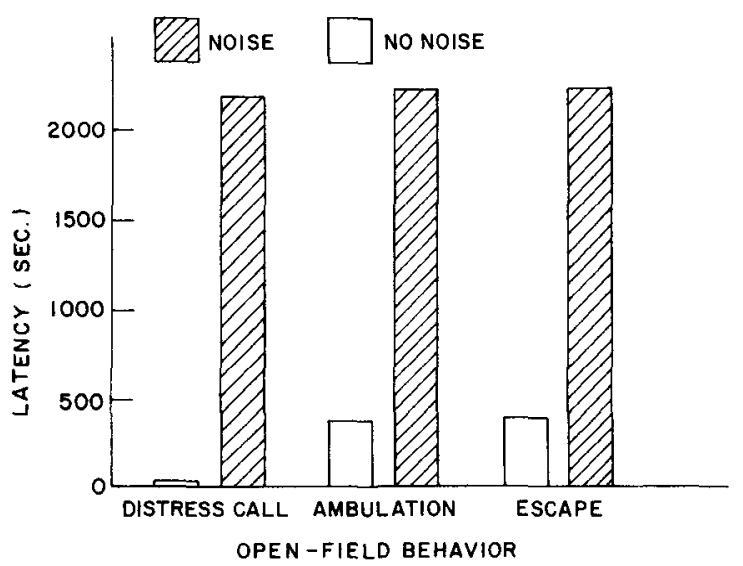

Figure 2. Mean distress-call, ambulation, and escape latencies following exposure to noise or no noise. times longer to begin distress calling than subjects not given pretest noise.

Analysis of variance of ambulation and escapeattempt latencies also showed significant differences between groups, with birds in the noise group taking longer to ambulate $[F(1,18)=41.02, \mathrm{p}<.001]$ and attempt to escape $[F(1,18)=40.73, p<.001]$ than those in the no-noise group. Differences between groups for defecation rate were also significant $[F(1,18)$ $=10.65, \mathrm{p}<.005]$, with subjects in the noise group defecating less often (mean $=.04 / \mathrm{min})$ than those in the no-noise group (mean $=.52 / \mathrm{min}$ ). Numbers of lines crossed and escape attempts were not analyzed because several birds in the noise group failed to leave the initial square within the allotted time of $40 \mathrm{~min}$, thus rendering comparisons between groups on these measures uninterpretable (see Discussion). Correlations between latencies and with defecation rate are shown in Table 1.

Thus, pretest noise not only increases tonic immobility duration, but also promoted freezing and silence in an open field.

\section{EXPERIMENT 4}

Manipulations designed to enhance fear generally potentiate durations of tonic immobility, while procedures which decrease fear attenuate the reaction (Gallup, 1974, 1977). As further support for the role of fear, systemic injections of adrenalin increase durations of tonic immobility in chickens (Braud \& Ginsburg, 1973; Thompson, Scuderi, \& Boren, 1977), lizards (Hoagland, 1928), and frogs (Klemm, 1977). The fourth experiment sought to determine whether adrenalin would produce a corresponding change in open-field behavior. According to our model, adrenalin should make the predatory overtones of the testing situation more salient and thereby result in a predominance of behaviors that minimize detectability.

\section{Method}

Subjects. The subjects were 32 straight-run Production Red chickens obtained and maintained as in the preceding studies.

Apparatus and Procedure. The same open field and video recording equipment were used, and testing was conducted during the same interval of the photoperiod and under the same level of illumination as described previously. At 19 days of age, the subjects were assigned randomly to one of two groups of 16 birds each. The subjects in one group were given an ip injection of DL-epinephrine (Sigma Co.) dissolved in distilled water at a dose of $1 \mathrm{mg} / \mathbf{k g}$, while those in the other group received the same volume $(2.5 \mathrm{ml} / \mathrm{kg})$ of the vehicle alone. Epinephrine dosage and injection-test interval were the same as that used by Thompson et al. (1977). After injection, each subject was leg-marked with a felt tip marker for identification and returned to a brooder with three other birds. Fifteen minutes later the bird was removed from the brooder, carried to the testing room in a cardboard box, and placed in the center square of the open field. All subjects were tested in the absence of an experimenter and were filmed from the time of placement until $3 \mathrm{~min}$ after leaving the center square. Videotapes were scored for distress call, ambulation, and escape laten- 


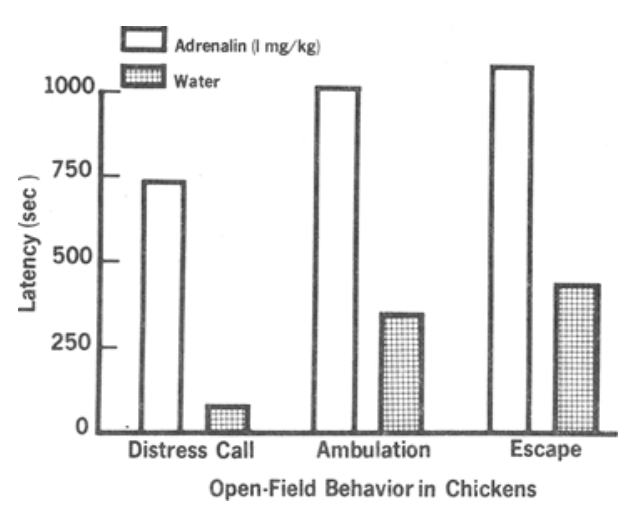

Figure 3. Mean distress-call, ambulation, and escape latencies for birds injected with adrenalin or water.

cies, numbers of lines crossed and escape attempts, and defecation rate, according to the procedure used in the preceding experiments.

\section{Results}

The data for distress call, ambulation, and escape latencies are shown in Figure 3. Analyses of variance of scores corrected for heterogeneity of variance by a $\log _{10}(x)$ transformation indicated that birds that received an injection of adrenalin took longer to begin distress calling $[\mathrm{F}(1,30)=9.78, \mathrm{p}<.005]$, ambulating $[F(1,30)=5.20, p<.05]$, and attempting to escape from the open field $[F(1,30)=5.47, p<.05]$ than subjects that were given the vehicle alone. Analyses of variance of numbers of lines crossed, number of escape attempts, and defecation rate failed to differentiate between groups. Correlational data are given in Table 1.

In summary, the effects on open-field behavior produced by adrenalin appear to be consistent with results previously reported on tonic immobility.

\section{EXPERIMENT 5}

Experiment 5 provides a means of testing the implications of our assertion that human contact simulates a predatory encounter. Birds that were placed in the open field by hand were compared with subjects that received no human contact during placement in the apparatus. According to our model, subjects contacted by a human should be more prone to exhibit responses that serve to minimize detectability, while the behavior of birds placed in the open field mechanically should primarily reflect attempts at reinstatement with conspecifics.

\section{Method}

Subjects. The subjects were 42 24-day-old straight-run Production Red chickens obtained and cared for as described previously.

Apparatus and Procedure. Testing was conducted during the same interval of the photoperiod, under the same intensity of il lumination in the same open field, and behavior was monitored with the same closed circuit television system as in the preceding studies. All birds were individually removed from a brooder, placed on a $30 \times 21.5 \mathrm{~cm}$ piece of cardboard and covered with a wire-mesh rat cage $(25.5 \times 19.0 \times 17.5 \mathrm{~cm}$ high $)$, and carried to the testing room. Twenty-one subjects, randomly assigned to one group, were removed from the transport container and placed in the center square of the open field by hand. For the remaining birds, the rat cage was removed and the subjects were gently tipped off the piece of cardboard into the center square. Open-field testing was conducted with the Plexiglas lid lowered and in the absence of an experimenter. Monitoring began at the time of placement and continued until $3 \mathrm{~min}$ after the bird left the center square. Latencies to distress call, ambulate out of the center square, and attempt to escape were timed, and numbers of lines crossed, escape attempts, and defecation rates were recorded, using the procedure described previously.

\section{Results}

The data for distress call and ambulation latencies are given in Figure 4. Following a $\log _{10}(x+1)$ transformation of scores to eliminate heterogeneity of variance, analyses of variance showed significant differences between groups, with birds placed in the open field by hand taking longer to begin distress calling $[\mathrm{F}(1,40)=21.30, \mathrm{p}<.001]$ and ambulating $[F(1,40)=4.75, p<.05]$ than birds receiving no human contact when placed in the open field. Although in the predicted direction (mean $=242.3 \mathrm{sec}$ for hand placement; mean $=93.8 \mathrm{sec}$ for mechanical placement), an analysis of variance of escape latency scores did not reach statistical significance. Numbers of lines crossed, escape attempts, and defecation rates also failed to differentiate between groups. Spearman rank-order correlations can be seen in Table 1.

Thus, human contact during placement in the open field results in an enhancement of behaviors hypothesized to minimize further predatory attack.

\section{EXPERIMENT 6}

Previous work has shown that prior repetitive handling decreases open-field freezing in rodents and chickens (e.g., Doty \& Doty, 1967; Ginsburg, Braud, \& Taylor, 1974; Goldman, 1965; Watson, Henry, \& Haltmeyer, 1974) and increases vocalization rates in

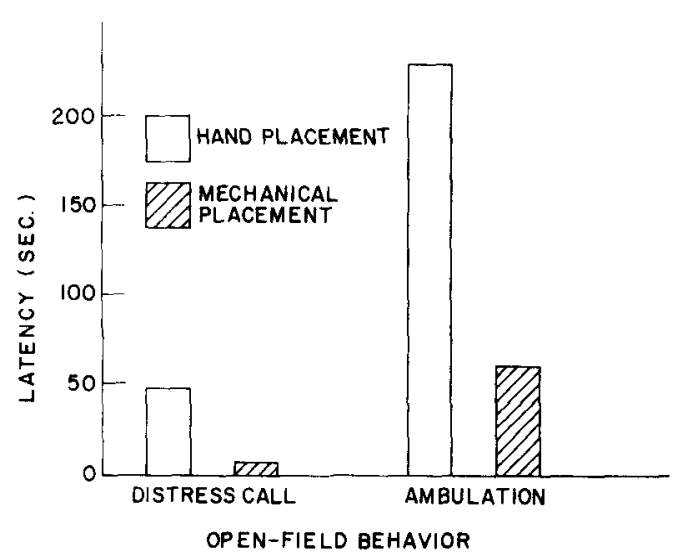

Figure 4. Mean distress-call and ambulation latency as a function of manual vs. mechanical placement in the open field. 
chickens (Ginsburg et al., 1974). We interpret these effects as being due to the fact that repeated human contact not resulting in injury produces habituation to the predator-like qualities of human experimenters (Gallup \& Suarez, 1980). Although prior handling has also been shown to produce abbreviated tonic immobility durations (Gilman, Marcuse, \& Moore, 1950; Ginsburg et al., 1974), habituation to tonic immobility by repeated inductions produces an even more profound response decrement (Nash \& Gallup, 1976).

In Experiment 6 the behavior of naive chicks in an open field was compared with the behavior of chicks which either received prior handling or were habituated to tonic immobility.

\section{Method}

Subjects. The subjects were 60 30-day-old straight-run Production Red chickens obtained and maintained as in the preceding experiments.

Apparatus and procedure. The same open field and video equipment were used, and testing was conducted under the same lighting and time-of-day conditions as previously described. On the day preceding open-field testing, 20 birds were assigned randomly to each of three groups. One group of subjects was habituated to tonic immobility by the following procedure: Each bird was individually removed from a brooder, transported to the testing room in a cardboard box, and placed on a table, where it was gently restrained on its right side for $15 \mathrm{sec}$. If the subjects had not terminated immobility within the following $15 \mathrm{sec}$, it was gently prodded until it righted itself. This procedure was repeated four additional times, with an interinduction interval of $30-45 \mathrm{sec}$. After habituation training, the subject was returned to a brooder.

The birds in the second group were subjected to a handling procedure which consisted of the following sequence of events: Each subject was taken from a brooder, carried to the testing room in a cardboard box, and placed on a table, where it was gently stroked and handled for $15 \mathrm{sec}$. After $30-45 \mathrm{sec}$ had elapsed, the procedure was repeated until the chick had received five episodes of handling, after which it was returned to a brooder.

The birds in the remaining group were left undisturbed until open-field testing on the following day. All subjects were given an open-field test using the same procedure and dependent variables as described previously.

\section{Results}

Figure 5 shows the data for distress call latencies. An analysis of variance of scores corrected for heterogeneity of variance by $a \log _{10}(x+1)$ transformation yielded an overall significant difference between groups $[F(2,57)=3.97, p<.03]$. An orthogonal decomposition of the data showed that birds habituated to tonic immobility had significantly shorter distress-call latencies than the handled and naive groups combined $[F(1,57)=6.70, p<.01]$, but that handled and naive groups did not differ from one another.

The data for ambulation latencies are shown in Figure 6. A $\log _{10}(x+1)$ transformation was performed on the scores to eliminate heterogeneity of variance, and a subsequent analysis of variance yielded no overall significant difference between groups. However, an orthogonal decomposition indicated

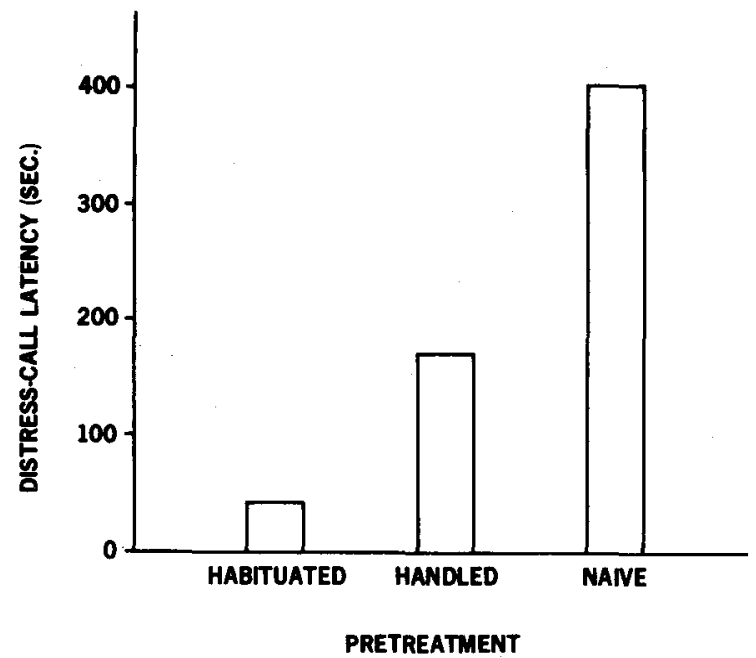

Figure 5. Mean distress-call latency on the part of habituated, handled, or naive chicks.

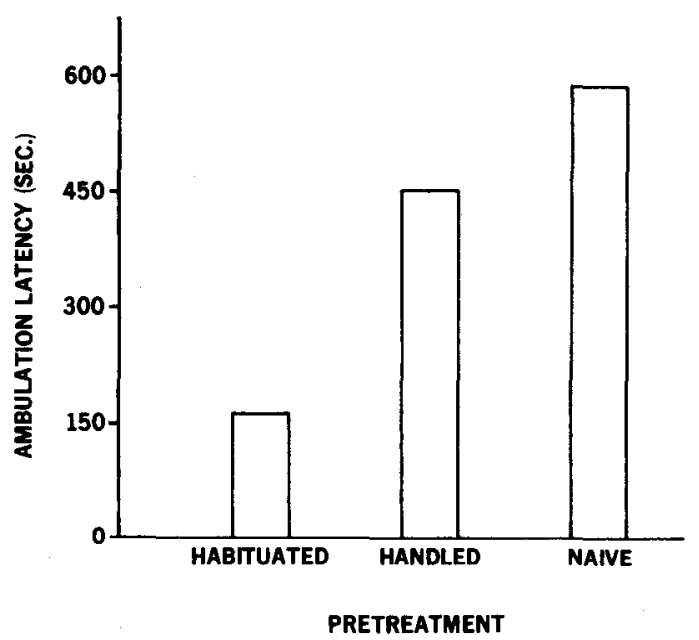

Figure 6. Mean ambulation latency on the part of habituated, handled, or naive chicks.

that habituated birds initiated ambulation sooner than the handled and naive groups combined $[F(1,57)$ $=4.01, p<.05]$ and that there was no difference between the handled and naive groups. An analysis of variance of number of lines crossed resulted in no overall difference between groups. An orthogonal comparison of habituated subjects with the naive and handled groups only approached significance $[F(1,57)$ $=3.05, p=.086$, with the habituated group showing a tendency to cross more lines (mean $=11.4$ ) than the handled (mean $=7.5$ ) and naive (mean $=8.3$ ) subjects. Handled and naive groups did not differ. An overall analysis of variance of escape attempts was not significant, nor was an orthogonal comparison of habituated subjects with the naive and handled groups. No difference was found between the habituated and handled groups, either. Defecation rates 
also failed to differentiate between groups. Neither an overall analysis of variance, a comparison between handled and naive subjects, nor a comparison of the habituated group with the handled and naive groups was significant. Spearman rank-order correlations between the different dependent variables are provided in Table 1.

In summary, chickens that had been habituated to tonic immobility prior to being tested were less prone to exhibit predator evasion behaviors than subjects that had either received handling or were left undisturbed before testing.

\section{EXPERIMENT 7}

The administration of a tranquilizer specially developed for domestic fowl (Pacitran) attenuates tonic immobility (Gallup, Nash, \& Brown, 1971; Gallup, Rosen, \& Brown, 1972). In the present study, openfield behavior of chicks given Pacitran was compared with that of nontranquilized birds. Based on the correspondence between tonic immobility and openfield behavior reported in the previous experiments, tranquilized birds should be less likely to show behaviors that would minimize cues that might elicit attack.

\section{Method}

Subjects. Thirty-two straight-run Production Red chickens obtained and cared for as described previously served as subjects. Testing was conducted at 24 days of age.

Apparatus and Procedure. Subjects were tested in the same open field under the same conditions as in the preceding studies. In the morning of the day of open-field testing, all subjects were water deprived for $4 \mathrm{~h}$. Sixteen randomly selected subjects were then given $15-\mathrm{min}$ access to a $4-\mathrm{mg} / \mathrm{kg}$ solution of the avian tranquilizer Pacitran (metoserpate $\mathrm{HCl}$; Gland-O-Lac $\mathrm{Co}$.), while the remaining subjects were allowed to drink plain water. Details pertaining to dosage and time parameters were taken from Gallup, Nash, and Brown (1971). After ingestion of the tranquilizer or water, each chick was removed from a brooder, carried to the testing room in a cardboard box, and placed in the center square of the open field. The experimenter left the room after lowering the Plexiglas lid. Behavior was recorded from the time of placement until 3 min after the chick left the center square. Distress call, ambulation, and escape latencies, numbers of lines crossed and escape attempts, and defecation rate were recorded as in the previous studies.

\section{Results}

Figure 7 depicts the latency data. An analysis of variance of distress-call latency scores corrected for heterogeneity of variance by a $\log _{10}(x+1)$ transformation yielded a significant difference between groups $F(1,30)=9.74, p<.005$ ], with birds that had been tranquilized distress calling sooner than control subjects. Analyses of variance of ambulation and escape latencies showed that birds that had been given Pacitran also ambulated sooner $[\mathrm{F}(1,30)=4.59, \mathrm{p}<.05]$ and took less time before attempting to fly out of the open field $[F(1,30)=4.70, p<.05]$. No significant

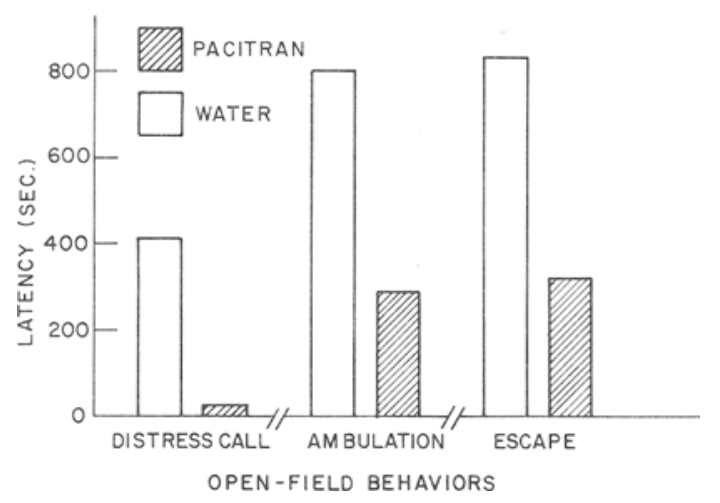

Figure 7. Mean distress-call, ambulation, and escape latencies for tranquilized vs. nontranquilized chicks.

differences between groups were found for number of lines crossed, escape attempts, or defecation rate. Spearman rank-order correlations are shown in Table 1 .

Thus, by decreasing fear in general and presumably fear of predation in particular, tranquilization produces comparable effects on tonic immobility and open-field behavior in that the propensity to exhibit defensive behavior is reduced.

\section{DISCUSSION}

The experiments reported here were conducted to ascertain, as a means of construct validation, whether a documented antipredator strategy could be used to predict open-field behavior. To this end, manipulations that have been shown to alter tonic immobility were used on chicks in an open field. It is important to note that the fact that variables that affect tonic immobility also affect open-field behavior does not mean that the two behaviors necessarily reflect common mechanisms. Although this remains an appealing possibility, the central issue is whether the approach we advocate has heuristic value.

Experiment 1 showed that open-field pretesting increased tonic immobility. Other investigators (Tortora \& Borschelt, 1972) have obtained results showing that elicitation of behaviors occurring earlier in the defensive distance sequence described by Ratner (1967) can enhance behaviors occurring later in that sequence. Our results lend support to this hypothesis. Moreover, the fact that merely confining subjects in an open field can enhance a behavior that has been independently implicated as a predator defense supports the proposition that open-field testing may contain overtones of predation.

Numerous studies have been conducted to assess the effects of the presence of a natural predator (e.g., Blanchard \& Blanchard, 1971; Blanchard, Mast, \& Blanchard, 1975; Bronstein \& Hirsch, 1976; Curti, 1935; Griffith, 1920; Hofer, 1970; Price, 1970; 
Satinder, 1976) or a human (Gallup \& Suarez, 1980) on activity patterns in several species. All of these studies report that behaviors that minimize detectability (i.e., inhibition of movement and vocalization) are enhanced when either a predator or a human is present. Both chickens (Gallup, Nash, Donegan, \& McClure, 1971) and lizards (Gallup, 1973) show potentiated tonic immobility durations when testing is conducted in the presence of a stuffed hawk. The presence of an experimenter produces the same effect (Edson \& Gallup, 1972; Gallup, Cummings, \& Nash, 1972).

Several experiments have yielded data indicating that for chickens the predator's eyes are particularly salient. When subjects are immobilized in front of a stuffed hawk with either a hood covering the hawk's head or with its eyes masked, durations of tonic immobility are abbreviated as compared with conditions in which the hawk's eyes are fully visible (Gallup, 1973; Gallup, Nash, Donegan, \& McClure, 1971). Likewise, longer durations are produced when the experimenter maintains direct eye contact with subjects than when the experimenter averts his gaze or completely avoids any eye contact (Gallup, Cummings, \& Nash, 1972).

More direct support for the fear-enhancing property of eyes comes from studies using artificial eyes as an independent variable. Subjects remain immobile longer when tested with detached eyes suspended overhead than when the eyes are blocked from view (Gallup, Nash, \& Ellison, 1971; O'Brien \& Dunlap, 1975). Interestingly, the only pupil-to-eye size ratio found effective in potentiating tonic immobility in chickens was that which most clearly resembles the average vertebrate predator eye (Gagliardi, Gallup, \& Boren, 1976). In light of these effects, Experiment 2 was conducted to determine if artificial eyes could be used to alter open-field behavior. The results showed that chicks tested with glass eyes suspended over the open field took longer to begin making separation calls (distress calling) and ambulating than those unable to see the eyes. The adaptive significance of being able to respond differentially to a predator's eyes seems obvious. During any stage of a predatory encounter, prey which can identify the direction of a predator's attention may have the greatest chance of escaping should the predator become distracted (see Gagliardi et al., 1976).

Sudden noise, which under natural conditions might signal an approaching predator, not only enhances tonic immobility duration (Edson \& Gallup, 1972; Gallup, Nash, Potter, \& Donegan, 1970; Nash et al., 1970), but also strongly promotes freezing and silence in an open field, as demonstrated in Experiment 3 . In fact, freezing in response to novel sounds is so reliable in at least one species that it has been used as an index of auditory thresholds (Miller \&
Murray, 1966). In Experiment 4, adrenalin also served to enhance behaviors in an open field that would be most adaptive during a predatory encounter (i.e., delayed initiation of movement and vocalization), and adrenalin has been shown to prolong tonic immobility (Braud \& Ginsburg, 1973; Hoagland, 1928; Klemm, 1977; Thompson et al., 1977).

While the first four studies all used methods to heighten the threat of predation, the remaining experiments were designed to decrease the predatory overtones of open-field testing. In agreement with a previous study using rats (Abel, 1971), elimination of human contact during open-field placement in Experiment 5 diminished the occurrence of predator evasion behaviors, which is consistent with our proposal that human contact simulates a predatory encounter.

In Experiment 6, habituated birds had shorter distress call and ambulation latencies than did handled or control subjects. While prior handling can be viewed as producing adaptation to predatory contact, habituation to tonic immobility would appear to have the potential of producing an even greater degree of adaptation. Most handling procedures stipulate that subjects are never physically restrained, only picked up and gently stroked. Thus, subjects are less compelled to show struggling or attempts to escape from the experimenter. Habituation to tonic immobility, on the other hand, encompasses prolonged physical restraint, usually accompanied by pronounced struggling and vigorous escape attempts. Thus, habituation to tonic immobility reduces not only the same responses that are elicited by handling, but also those behaviors (i.e., fighting and struggling) that occur later in the sequence. Although in the predicted direction, we failed, however, to find significant differences between naive and handled birds. This failure may be due to the fact that chicks in our experiment were given only 1 day of handling. Previous research demonstrating a handling-induced enhancement of distress calling and ambulating employed 6 days of handling (Ginsburg et al., 1974).

A possibly analogous finding on the effects of adaptation to a predatory encounter involves the effects of repetitive open-field testing. Jones (1977) and Montevecchi, Gallup, and Dunlap (1973) report that latencies to distress call and ambulate in chicks diminish over successive test episodes. As subjects are tested across days, responses to the predatory overtones of the test procedure would be expected to subside, thereby, in our view, increasing the probability of behaviors aimed at reestablishing social contact.

In Experiment 7, the open-field behavior of chicks given an avian tranquilizer (Pacitran) was compared with that of nontranquilized birds. As found in studies of tonic immobility (Gallup, Nash, \& Brown, 1971; Gallup, Rosen, \& Brown, 1972), tranquiliza- 
tion decreased the probability of defensive responses, producing instead a predominance of social reinstatement behaviors (i.e., distress calling, attempting to escape from the open field).

Several other manipulations which increase or decrease threat of predation also produce similar results on tonic immobility and open-field behavior. Pretest shock, which can be thought of as analogous to having been bitten, not only increases tonic immobility duration in many species (Edson \& Gallup, 1972; Gallup, Creekmore, \& Hill, 1970; Gallup, Nash, Potter, \& Donegan, 1970), but also profoundly suppresses movement in both rodents and avians and vocalization in birds (Anderson, Crowell, Koehn, \& Lupo, 1976; Baron, 1964; Blanchard \& Blanchard, 1969; Gallup \& Suarez, 1980; Levine, Madden, Conner, Moskal, \& Anderson, 1973; Montevecchi et al., 1973; Pinel, Corcoran, \& Malsbury, 1971). Similarly, a cue previously paired with shock, or which, by analogy, signals an impending predatory encounter, both prolongs tonic immobility (Gallup, Rosen, \& Brown, 1972) and inhibits activity and vocalization in an open field (Bindra \& Palfai, 1967; Gallup \& Suarez, 1980; Mikulka, Kendall, Constantine, \& Porterfield, 1972; Murai, 1968).

Experiment 1 showed that both distress call and ambulation latencies were positively correlated with tonic immobility duration, a finding that is consistent with previous work (Gallup, Ledbetter, \& Maser, 1976; Gallup, Nash, \& Wagner, 1971). Table 1 shows that distress-call latency is also significantly and positively correlated with ambulation latency in 12 of 13 , or over $90 \%$, of the groups tested. The fact that the initiation of distress calling can be used to predict both the termination of freezing in the present study and tonic immobility (Gallup, Nash, \& Wagner, 1971) may be indicative of an adaptive strategy. Given the importance of movement cues in triggering predatory orientation and attack, distress calling, after a period of silence, may serve as a means of testing the surroundings for predatory cues prior to the resumption of movement (Gallup \& Suarez, 1980).

Other evidence indicating a relationship between tonic immobility and open-field behavior comes from studies of strain differences and the effects of selective breeding. White Leghorn chickens not only show significantly longer durations of tonic immobility, but also have longer latencies to distress call and ambulate in an open field than do Production Reds (Gallup et al., 1976). Furthermore, and perhaps more directly related to the question of a common mechanism underlying both tonic immobility and the timing of reactions in an open field, Faure (1975) reports that selectively breeding for longer bouts of freezing and silence by chickens in an open field produces birds which show a concomitant increase in tonic immobility duration.
Evidence that exploration is not the motivation for movement upon initial exposure to an open field is also provided in Table 1. In all of the groups tested, significant positive correlations were found between ambulation and escape latencies. Furthermore, in 9 of 11 groups, significant positive correlations were found between number of lines crossed and escape attempts. We submit that the initiation and maintenance of open-field activity is initially motivated not by a tendency to explore the environment but, rather, by attempts to escape from the confines of the apparatus. In this context, the absence of group differences in any experiment for number of lines crossed or escape attempts merits some discussion. First of all, our testing procedure differs from that employed in most other open-field studies. While other researchers use a fixed time interval which begins when a subject is placed in the apparatus, fixed recording periods in our studies do not begin until after a subject leaves the center square of the field. With the more traditional method, differences between groups in the number of times a particular behavior occurs is confounded with the latency to first perform that behavior. During a predatory encounter, the latency to respond, rather than the number of times a response occurs, may be the important variable in determining outcome. One can speculate that activity in an open field does not begin until after the animal has sensed that the danger of a predatory encounter has passed. In the experiments reported here, the procedures were designed to vary the threat of predation, while holding social reinstatement tendencies constant. It is not surprising, then, to find that, once activity begins, no differences are found between groups in their attempts at social reinstatement.

Although some of our findings (i.e., the chemical manipulations) could be accounted for by the general emotionality hypothesis, others are more difficult to explain by a post hoc appeal to emotionality. For example, there is no obvious explanation in terms of emotionality for the results of Experiment 6, in which birds habituated to tonic immobility began moving and vocalizing sooner than previously handled subjects. Similarly, it is not clear how the effects of artificial eyes or human contact on the inhibition of movement and vocalization in an open field found in Experiments 2 and 5 can be explained a priori in terms of differences in emotionality.

Murphy and Wood-Gush (1978) have argued that there can be no standardized open-field test for domestic fowl because of apparent inconsistencies in their results due to age, strain, and prior social experience. However, due to several sources of covariation in their study (e.g., type of caging, amount of handling, and method of transport to the testing area all varied with age; activity measures in some cases were confounded with time spent in the transport 
box; some birds were tested in open fields of different sizes and under different lighting conditions), it is difficult to know whether the obtained differences were a consequence of differences among birds or of differences in method. Murphy (1978) further argues that, in laboratory investigations of fear in domestic fowl, the nature of the artificial environment prevents the performance of natural responses even when natural dangers are mimicked. Thus, she classifies sitting or standing with the beak on the ground or "sleeping" by chicks in a novel environment as abnormal behavior patterns. However, we propose that such behaviors, rather than being abnormal, serve to decrease detectability. Sitting or crouching upon detecting a predator is a common response under natural conditions in the young of many precocial avian species, and "pseudosleeping" has been observed in wild birds of various species in response to an approaching human (Cornwell \& Bartonex, 1963; Williamson, 1950). Eye closure itself has been proposed as a method of concealment in species in which the eyelid, rather than the eye, matches the coloration of the surrounding skin (Cott, 1940).

In summary, the experiments reported here show that manipulations which prolong tonic immobility produce a corresponding increase in open-field behaviors that have been hypothesized to minimize detectability and/or discourage further attack under natural conditions. On the other hand, procedures which abbreviate tonic immobility lessen the probability of such defensive responses and increase the likelihood of behaviors associated with attempts to reestablish contact with conspecifics (i.e., distress calling, attempting to escape).

\section{REFERENCES}

ABEL, E. L. Habituation as a factor in early handling. Journal of Comparative and Physiological Psychology, 1971, 74, 219-221.

Anderson, D. C., Crowell, C., Koehn, D., \& Lupo, J. V. Different intensities of unsignalled inescapable shock treatments as determinants of non-shock-motivated open field behavior: A resolution of disparate results. Physiology \& Behavior, 1976, 17, 391-394.

ANDREw, R. J. Fear responses in Emberiza Spp. British Journal of Animal Behaviour, 1956, 4, 125-132.

Archer, J. Tests for emotionality in rats and mice. A review. Animal Behaviour, 1973, 21, 205-235.

Armstrong, E. A. The wren. London: Collins, 1955.

Armstrong, E. A. Bird display and behaviour. New York: Dover, 1965.

Askew, H. R., Musimeci, M., Sloane, L., \& Stephan, L. Effects of prey movement and background on predatory behavior of chameleons. Psychonomic Science, 1970, 20, 171.

Baron, A. Suppression of exploratory behavior by aversive stimulation. Journal of Comparative and Physiological Psychology, $1964,57,299-301$.

Bindra, D., \& Palfai, T. Nature of positive and negative incentive-motivational effects on general activity. Journal of Comparative and Physiological Psychology, 1967, 63, 288-297.

Blanchard, R. J., \& Blanchard, D. C. Crouching as an index of fear. Journal of Comparative and Physiological Psychology, $1969,67,370-375$.
Blanchard, R. J., \& Blanchard, D. C. Defensive reactions in the albino rat. Learning and Motivation, 1971, 2, 351-362.

Blanchard, R. J., Mast, M., \& Blanchard, D. C. Stimulus control of defensive reactions in the albino rat. Journal of Comparative and Physiological Psychology, 1975, 88, 81-88.

Braud, W. G., \& Ginsburg, H. J. Effect of administration of adrenalin on immobility reaction in domestic fowl. Journal of Comparative and Physiological Psychology, 1973, 83, 124-127.

Bronstein, P. M., \& Hirsch, S. M. Ontogeny of defensive reactions in Norway rats. Journal of Comparative and Physiological Psychology, 1976, 90, 620-629.

BrüCKner, G. H. Untersuchungen zur Tiersoziologie, inbesondre der Auflosung der Familie. Zeitschrift für Psychologie, 1933, 128, 1-120.

Burghardt, G. M. Stimulus control of the prey attack response in naive garter snakes. Psychonomic Science, 1966, 4, 37-38.

Busnel, R. G. Aspects of animal acoustic signals. In R. G. Busnel (Ed.), Acoustic behavior of animals. New York: Elsevier, 1963.

Collias, N. E. The development of social behavior in birds. $A u k, 1952,69,127-159$.

Collias, N. E., \& Collias, E. C. Some mechanisms of family interaction in ducks. $A u k, 1956,73,378-400$.

Connwell, G. W., \& Bartonex, J. C. Pseudo-sleeping attitude of the canvasback. Condor, 1963, 65, 444-446.

CoTt, H. B. Adaptive coloration in animals. New York: Oxford University Press, 1940.

Curio, E. The ethology of predation. Berlin: Springer-Verlag, 1976.

Curti, M. W. Native fear responses of white rats in the presence of cats. Psychological Monographs, 1935, 46, 78-98.

Doty, B. A., \& Doty, L. A. Effects of handling at various ages on later open-field behavior. Canadian Journal of Psychology, $1967,21,463-470$.

Drummond, H. M. Stimulus control of amphibious predation in the northern water snake (Nerodia s. sipedon). Zeitschrift für Tierpsychologie, 1979, 50, 18-44.

Edson, P. H., \& Gallup, G. G., JR. Tonic immobility as a fear response in lizards (Anolis carolinensis). Psychonomic Science, $1972,26,27-28$.

Faure, J. M. Étude des liaisons entre comportement en openfield et émotivité chez le jeune poussin. Annales de Génétique et de Sélection Animale, 1975, 7, 197-204.

Fox, M. W. Ontogeny of prey-killing behavior in Canidae. Behaviour, 1969, 35, 259-272.

Gagliardi, G. J., Gallup, G. G., Jr., \& Boren, J. L. Effect of different pupil to eye size ratios on tonic immobility in chickens. Bulletin of the Psychonomic Society, 1976, 8, 58-60.

GalluP, G. G., JR. Simulated predation and tonic immobility in Anolis carolinensis. Copeia, 1973, 623-624.

Gallup, G. G., JR. Animal hypnosis: Factual status of a fictional concept. Psychological Bulletin, 1974, 81, 836-853.

Gallup, G. G., JR. Tonic immobility: The role of fear and predation. Psychological Record, 1977, 27, 41-61.

Gallup, G. G., Jr., Creekmore, H. S., \& Hill, W. E., III. Shock-enhanced immobility reactions in chickens: Support for the fear hypothesis. Psychological Record, 1970, 20, 243-245.

Gallup, G. G., Jr., Cummings, W. H., \& Nash, R. F. The experimenter as an independent variable in studies of animal hypnosis in chickens (Gallus gallus). Animal Behaviour, 1972, 20, 166-169.

Gallup, G. G., JR., Ledhetter, D. H., \& Maser, J. D. Strain differences among chickens in tonic immobility: Evidence for an emotionality component. Journal of Comparative and Physiological Psychology, 1976, 90, 1075-1081.

Gallup, G. G., Jr., Nash, R. F., \& Brown, C. W. The effects of a tranquilizer on the immobility reaction in chickens: Additional support for the fear hypothesis. Psychonomic Science, $1971,23,127-128$.

Gallup, G. G., Jr., Nash, R. F., Donegan, N. H., \& McClure, M. K. The immobility response: A predator-induced reaction in chickens. Psychological Record, 1971, 21, 513-519.

Gallup, G. G., Jr., Nash, R. F., \& Ellison, A. L., Jr. Tonic 
immobility as a reaction to predation: Artificial eyes as a fear stimulus for chickens. Psychonomic Science, 1971, 23, 79-80.

Gallup, G. G., Jr., Nash, R. F., Potter, R. J., \& Donegan, N. H. Effects of varying conditions of fear on immobility reactions in domestic chickens (Gallus gallus). Journal of Comparative and Physiological Psychology, 1970, 73, 442-445.

Gallup, G. G., Jr., Nash, R. F., \& Wagner, A. M. The tonic immobility reaction in chickens: Response characteristics and methodology. Behavior Research Methods \& Instrumentation, 1971, 3, 237-239.

Gallup, G. G., JR., Rosen, T. S., \& Brown, C. W. Effect of conditioned fear on tonic immobility in domestic chickens. Journal of Comparative and Physiological Psychology, 1972, 78, 22-25.

Gallup, G. G., Jr., \& Suarez, S. D. An ethological analysis of open-field behaviour in chickens. Animal Behaviour, 1980, 28, 368-378.

Gilman, T. T., Marcuse, F. L., \& Moore, A. U. Animal hypnosis: A study in the induction of tonic immobility in chickens. Journal of Comparative and Physiological Psychology, 1950, 43, 99-111.

Ginsburg, H. J., Braud, W. G., \& Taylor, R. D. Inhibition of distress vocalizations in the open field as a function of heightened fear or arousal in domestic fowl (Gallus gallus). Animal Behaviour, 1974, 22, 745-749.

Goldman, P. S. Conditioned emotionality in the rat as a function of stress in infancy. Animal Behaviour, 1965, 13, 434-442.

Griffith, C. R. The instinctive behavior of white rats in the presence of cats. Psychobiology, 1920, 2, 19-28.

HEDIGER, H. Studies on the psychology and behavior of captive animals in zoos and circuses. London: Butterworth, 1955.

Herzog, H. A., Jr., \& Burghardt, G. M. Prey movement and predatory behavior of juvenile western yellow-bellied racers, Coluber constrictor mormon. Herpetologica, 1974, 30, 285-289.

Hoagland, $H$. The mechanism of tonic immobility ("animal hypnosis"'). Journal of General Psychology, 1928, 1, 426-447.

Hofe r, M. A. Cardiac and respiratory function during sudden prolonged immobility in wild rodents. Psychosomatic Medicine, 1970, 32, 633-647.

JoNEs, R. B. Repeated exposure of the domestic chick to a novel environment: Effects on behavioral responses. Behavioral Processes, 1977, 2, 163-173.

KaUfman, D. W. Differential predation on active and inactive prey by owls. $A u k, 1974,91,172-173$.

KING, J. A. Social relations of the domestic guinea pig living under semi-natural conditions. Ecology, 1956, 37, 221-228.

KLEMM, W. R. Identity of sensory and motor systems that are critical to the immobility reflex ("animal hypnosis"). Psychological Record, 1977, 27, 145-159.

KRUiJT, J. P. Ontogeny of social behavior in Burmese Red Jungle fowl (Gallus gallus spadiceus) bonnaterre. Behaviour Supplement XII. Leiden: Brill, 1964.

LEOPOLD, A. S. The nature of heritable wildness in turkeys. Condor, 1944, 46, 133-147.

Levine, S., Madden, J., IV, Conner, R. L., Moskal, J. R., \& Anderson, D. C. Physiological and behavioral effects of prior aversive stimulation (pre-shock) in the rat. Physiology \& Behavior, 1973, 10, 467-471.

MacDonald, L. Attack latency of Constrictor constrictor as a function of prey activity. Herpetologica, 1973, 29, 45-48.

Mikulka, P., Kendall, P., Constantine, J., \& Porterfield, L. The effect of Pavlovian CS+ and CS- on exploratory behavior. Psychonomic Science, 1972, 27, 308-310.

Miller, J. D., \& Murray, F. S. Guinea pig's immobility response to sound: Threshold and habituation. Journal of Comparative and Physiological Psychology, 1966, 61, 227-233.

Montevecchi, W. A., Gallup, G. G., JR., \& DunlaP, W. P. The peep vocalization in group reared chicks (Gallus domesticus): Its relation to fear. Animal Behaviour, 1973, 21, 116-123.

Murai, N. Effects of experience upon the open field behavior in rats: 1. A study of the differentiation of active and passive avoidance responses. Tohoku Psychologica Folia, 1968, 27, 50-56.

MURPyY, L. B. The practical problems of recognizing and measuring fear and exploration in the domestic fowl. Animal Behaviour, 1978, 26, 422-431.

Murphy, L. B., \& Wood-Gush, D. G. M. The interpretation of the behaviour of domestic fowl in strange environments. Biology of Behaviour, 1978, 3, 39-61.

Nash, R. F., \& Gallup, G. G., JR. Habituation and tonic immobility in domestic chickens. Journal of Comparative and Physiological Psychology, 1976, 90, 870-876.

Nash, R. F., Gallup, G. G., Jr., \& McClure, M. K. The immobility reaction in leopard frogs (Rana pipiens) as a function of noise-induced fear. Psychonomic Science, 1970, 21, 155-156.

NoвLE, G. K. The biology of the amphibia. New York: McGrawHill, 1931 .

O'Brien, T. J., \& Dunlap, W. P. Tonic immobility in the blue crab (Callinectes sapidus, Rathbun): Its relation to threat of predation. Journal of Comparative and Physiological Psychology, 1975, 89, 86-94.

Palmer, W. Instinctive stillness in birds. $A u k, 1909,26,23-36$.

Pinel, J. P., Corcoran, M. E., \& Malsbury, C. W. Incubation effects in rats: Decline of foot-shock-produced activation. Journal of Comparative and Physiological Psychology, 1971, 77, 271-276.

Price, E. Differential reactivity of wild and semi-domestic deermice (Peromyscus maniculatus). Animal Behaviour, 1970, 18, 747-752.

RATNER, S. C. Comparative aspects of hypnosis. In J. E. Gordon (Ed.), Handbook of clinical and experimental hypnosis. New York: Macmillan, 1967.

Sargeant, A. B., \& Eberhardt, L. E. Death feigning by ducks in response to predation by red foxes (Vulpes fulva). American Midland Naturalist, 1975, 94, 108-119.

SATINDER, K. P. Reactions of selectively bred strains of rats to a cat. Animal Learning \& Behavior, 1976, 4, 172-176.

Sisk, M. E. Notes on the feeding of a captive snake, Farancia abacura reinwardti. Herpetologica, 1963, 19, 221-222.

Stuck IN, W. Imprinting and early learning. Chicago: Aldine, 1965.

Smith, G. C., \& W ATSON, D. Selection patterns of corn snake, Elaphe guttata, of different phenotypes of the house mouse, Mus musculus. Copeia, 1972, 529-532.

StoddaRd, H. L. The babwhite quail: Its habits, preservation and increase. New York: Scribner's, 1936.

Stokes, A. W. Behavior of the bobwhite, Colinus virginianus. Auk, 1967, 84, 1-33.

Suarez, S. D., \& Gallup, G. G., JR. Tonic immobility as a response to rape in humans: A theoretical note. Psychological Record, 1979, 29, 315-320.

Thompson, R. K. R., Foltin, R. W., Boylan, R. J., Sweet, A. Graves, C. A., \& Lowitz, C. E. Tonic immobility in Japanese quail can reduce the probability of sustained attack by cats. Animal Learning \& Behavior, 1981, 9, 145-149.

Thompson, R. W., Scuderi, R., \& Boren, J. The effect of epinephrine on tonic immobility (animal hypnosis) in chickens. Bulletin of the Psychonomic Society, 1977, 9, 409-410.

Tortora, D. F., \& Borschelt, P. L. The effect of escape responses on immobility in bobwhite quail (Colinus virginianus). Psychonomic Science, 1972, 27, 129-130.

Walsh, R. N., \& Cummins, R. A. The open-field test: A critical review. Psychological Bulletin, 1976, 83, 482-504.

Watson, F. M. C., Henry, J. P., \& Haltmeyer, G. C. Effects of early experience on emotional and social reactivity in CBA mice. Physiology \& Behavior, 1974, 13, 9-14.

White, C. M., \& WeEDEN, R. B. Hunting methods of gyrfalcons and behavior of their prey (ptarmigan). Condor, 1966, 68, 517-519.

Williamson, $K$. The pseudo-sleeping attitude of the oystercatcher. British Birds. 1950, 43, 1-4.

(Received for publication December 5, 1980; accepted December 12, 1980.) 